\title{
The 24-hour pulse wave velocity, aortic augmentation index, and central blood pressure in normotensive volunteers
}

This article was published in the following Dove Press journal:

Vascular Health and Risk Management

28 April 2014

Number of times this article has been viewed

\section{Tatyana Y Kuznetsova' \\ Viktoria A Korneva' \\ Evgeniya $\mathrm{N}$ Bryantseva ${ }^{2}$ \\ Vitaliy S Barkan² \\ Artemy V Orlov ${ }^{3}$ \\ Igor N Posokhov ${ }^{4}$ \\ Anatoly N Rogoza ${ }^{5}$ \\ On behalf of BPLab- \\ Vasotens registry \\ collaborators}

'Faculty of Medicine, Petrozavodsk State University, Petrozavodsk, Russia; ${ }^{2}$ Diagnostics Department, The hospital within the Russian Railroad Network,

Chita, Russia; ${ }^{3}$ Department 65

Competitive System Analysis, National Research Nuclear University MEPhl, Moscow, Russia; ${ }^{4}$ Hemodynamic Laboratory Ltd, Nizhniy Novgorod, Russia; ${ }^{5}$ Cardiology Research Center, Moscow, Russia
Correspondence: Igor N Posokhov Hemodynamic Laboratory Ltd, PO Box 69, Nizhniy Novgorod 603009, Russia

Tel +7 9l 59396222

$\mathrm{Fax}+7913825$ 9ाII

Email posokhov@24h-monitoring.com

\begin{abstract}
The purpose of this study was to examine the pulse wave velocity, aortic augmentation index corrected for heart rate 75 (AIx@75), and central systolic and diastolic blood pressure during 24-hour monitoring in normotensive volunteers. Overall, 467 subjects (206 men and 261 women) were recruited in this study. Participants were excluded from the study if they were less than 19 years of age, had blood test abnormalities, had a body mass index greater than $27.5 \mathrm{~kg} / \mathrm{m}^{2}$, had impaired glucose tolerance, or had hypotension or hypertension. Ambulatory blood pressure monitoring (ABPM) with the BPLab ${ }^{\circledR}$ device was performed in each subject. ABPM waveforms were analyzed using the special automatic Vasotens ${ }^{\circledR}$ algorithm, which allows the calculation of pulse wave velocity, AIx@75, central systolic and diastolic blood pressure for "24-hour", "awake", and "asleep" periods. Circadian rhythms and sex differences in these indexes were identified. Pending further validation in prospective outcome-based studies, our data may be used as preliminary diagnostic values for the BPLab ABPM additional index in adult subjects.
\end{abstract}

Keywords: ambulatory, monitoring, arterial stiffness, augmentation index, central blood pressure, reference values

\section{Introduction}

Since the start of the new millennium, registries to assess the impact of ambulatory blood pressure monitoring (ABPM) on hypertension management and related outcomes have been established in several countries. ABPM registries are more commonly focused on patients with documented or possible hypertension who would benefit from ABPM. ${ }^{1}$ The BPLab-Vasotens registry that was established this year is the project of dozens of small groups aimed at joint solutions for various scientific problems. One of the challenges is research into new ABPM vascular indexes. Some of these indexes, such as pulse wave velocity (PWV), are recommended for practical clinical use, whereas others, such as central blood pressure (BP) and augmentation index (AIx), are indexes of great interest for mechanistic analyses in pathophysiology, pharmacology, and therapeutics, but more investigation is needed before recommending their routine clinical use. ${ }^{2}$ It is also necessary to note that at the present time, there are devices that provide not only a single pulse wave measurement but several pulse wave measurements over a period of 24 hours. ${ }^{3,4}$

The purpose of this study is to examine the PWV, aortic AIx corrected for heart rate 75 (AIx@75), and central systolic and diastolic blood pressure (SBPao and DBPao, respectively) during 24-hour monitoring in normotensive volunteers. 


\section{Materials and methods}

\section{Baseline characteristics}

Participants were screened for medical history and submitted to physical exams, blood tests (including lipid profile and glucose), and echocardiography with 12-lead electrocardiography. Individuals were excluded from the study if they were less than 19 years of age, had blood test abnormalities, had a body mass index greater than $27.5 \mathrm{~kg} / \mathrm{m}^{2}$, had impaired glucose tolerance, or had hypotension or hypertension.

Overall, 467 Caucasian subjects (66 men and 67 women under the age of 34, 75 men and 83 women aged 35-49, 65 men and 76 women aged 50-64, and 35 women aged 65 or over) were recruited in this study after providing written informed consent for participation. The study was approved by the local ethical committee.

\section{Measurements}

ABPM with the BPLab $^{\circledR}$ device (Petr Telegin, Nizhny Novgorod, Russia) was performed on each subject. The accuracy of this device has previously been validated for ABPM. ${ }^{5}$ There have been other validations for vascular indexes. ${ }^{6-8}$ The principle of the oscillometric method is based on plethysmography and registers pulsatile pressure changes in the brachial artery. The recordings were made in ambulatory conditions using a conventional brachial BP cuff for adults. During the BP measurement the pressure waveforms in the cuff are registered, digitalized, and stored in the device while performing a step-by-step deflation.

The ABPM waveforms were analyzed by a special automatic mathematical algorithm using BPLab Vasotens ${ }^{\circledR}$ technology (Petr Telegin), which allows calculation of central pulse wave parameters from the peripheral pulse wave. An aortic pulse wave is generated with a generalized transfer function that uses a modification of a certain frequency range within the acquired pulse signal to derive the aortic pressure wave. The modulus and phase characteristics of the Vasotens transfer function have previously been published. ${ }^{7}$ The principle of the PWV measurement of the Vasotens has also previously been described. ${ }^{4,6}$ The difference in time between the first wave and the second (ie, the reflected wave) is related to the distance measure according to the manufacturer's instructions, and the resulting PWV is in $\mathrm{m} /$ second. PWV, AIx@75, SBPao and DBPao were calculated for "24-hour", "awake", and "asleep" periods.

Quality control consisted of a visual assessment of the curves on the Vasotens clinical report screen. There was an average of 49 (standard deviation $=8.3$ ) successful readings during the monitoring period.

\section{Statistics}

BPStat $^{\circledR}$ software version 05.01 (Petr Telegin) enabled the automatic tabulation of all indexes of every measured waveform used. Statistica 8.0 (StatSoft Inc., Tulsa, OK, USA) and MedCalc (MedCalc Software, Ostend, Belgium) software were used for the analysis. Mean and standard deviation were used in the descriptive statistics. The association between age, sex, and time of day (awake or asleep) with PWV, AIx@75, and central BP of the subjects was determined using a multiple regression analysis. The strength of the association assessed by the multiple regression analysis was indicated by the standardized regression coefficient value (Beta). We also used the percentile method to estimate the reference intervals.

\section{Results}

Table 1 describes the PWV, AIx@75, SBPao, and DBPao in the male and female study participants. Men demonstrated significantly $(P<0.01)$ higher 24-hour PWV in the 50-64-year-old age group $(9.3 \mathrm{~m} / \mathrm{second})$ compared with women in the same age group ( $8.3 \mathrm{~m} / \mathrm{second})$. Furthermore, the 24-hour PWV in men increased with age significantly ( 7.8 versus $9.32 \mathrm{~m} /$ second, $P<0.01$ ), whereas women did not display a significant increase with age ( 7.9 versus 8.3 $\mathrm{m} / \mathrm{second}, P>0.05$ ). Both men and women in all age groups displayed a significant nocturnal fall of PWV.

Conversely, women displayed significantly $(P<0.01)$ higher 24-hour AIx@75 in the 50-64-year-old age group (27.0\%) compared with men of the same age (23.3\%). It should be noted that the nocturnal shift of AIx@75 was not significant.

Regarding the central aortic BP, both men and women displayed a characteristic nocturnal pattern similar to the "dipping" status of the peripheral pressure. There was an increase of 24-hour central aortic BP with age in men (systolic: 107.5 for age $<34$ years versus 114.5 for the $50-64$-year-old age group, $P<0.01$; diastolic: 71.3 for ages $<34$-years-old versus 81.0 for ages $50-64, P<0.01$ ) and in women (systolic: 103.1 for age $<34$-years-old versus 112.5 for $50-64$-yearsold, $P<0.01$; diastolic: 70.3 for age $<34$-years-old versus 73.7 for 50-64-years-old, $P<0.01$ ).

Most of the studied indexes showed significant association with time of day after multiple adjustments for age and sex (Table 2).

\section{Discussion}

The main result of the present study is the establishment of normal and reference values for indexes of Vasotens technology, namely PWV, central BP, and AIx@75. These values are based on a dataset obtained from four centers distributed across Russia. 


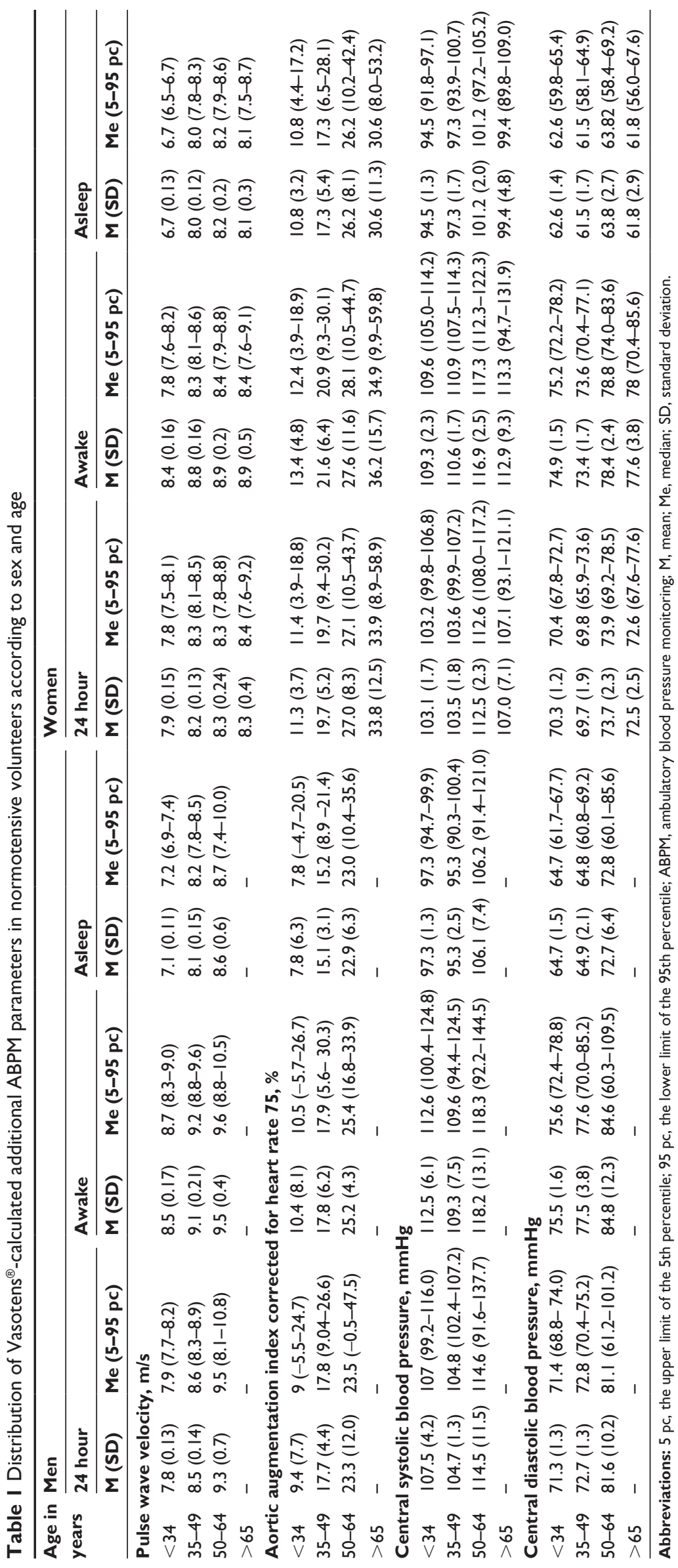


Table 2 Multiple regression results for the relationship between pulse wave velocity, aortic augmentation index corrected for heart rate 75 , and central systolic and diastolic blood pressure with variables studied

\begin{tabular}{|c|c|c|c|c|c|c|c|c|}
\hline & \multicolumn{2}{|l|}{ PWV } & \multicolumn{2}{|c|}{ Alx@75 } & \multicolumn{2}{|c|}{ SBPao } & \multicolumn{2}{|c|}{ DBPao } \\
\hline & Beta & P-level & Beta & P-level & Beta & P-level & Beta & P-level \\
\hline Time of day (awake or asleep) & 0.40 & 0.0003 & 0.11 & 0.0731 & 0.44 & 0.0004 & 0.42 & 0.0004 \\
\hline Age & 0.24 & 0.0203 & 0.19 & 0.0459 & 0.29 & 0.0309 & 0.23 & 0.0413 \\
\hline Sex & 0.23 & 0.0442 & 0.27 & 0.0273 & 0.20 & 0.0464 & 0.17 & 0.0623 \\
\hline
\end{tabular}

Abbreviations: Alx@75, aortic augmentation index corrected for heart rate 75; Beta, standardized regression coefficient value; DBPao, central diastolic blood pressure; PWV, pulse wave velocity; SBPao, central systolic blood pressure.

From a practical viewpoint, the accurate determination of PWV cut-off value excesses is an important task. This task allows physicians to draw conclusions about the significant alterations of aortic function and, accordingly, to include a patient in one risk group or another. It is evident that the representation of PWV values according to age is similar to the representation of the data reported in other published reports. ${ }^{9-11}$ According to some studies, there is nocturnal fall in PWV. ${ }^{2}$ However, in our study, normal and reference values for the night PWV, according to sex and age, have been published for the first time.

Interestingly, women in this study had a significantly lower PWV compared to men. It is well known that clinical and autopsy observations have suggested that women seem to develop vascular disease later than men, which could be related to factors specific to women that account, for example, for resistance to atheroma growth, etc. ${ }^{12,13}$

The circadian rhythms of central BP were also observed. Brachial and central BP both demonstrated typical diurnal patterns with lower pressures at night. Nighttime central BP may provide prognostic importance and warrants further investigation. ${ }^{14,15}$ Our study adds data to the above information on sex differences in central BP.

The relationship of the AIx to sex has recently been reported. ${ }^{16}$ Sex-specific equations including age, heart rate, and height to calculate reference values for AIx have also been validated. ${ }^{17}$ The AIx@75 in our study is corrected for heart rate, but it still has the most pronounced sex differences.

There were limitations associated with this study. The number of normotensive men over 65-years-old was too low, thus limiting our ability to detect significant differences in that age group. Studies involving a large number of patients are essential to generalize the results of the study. This study did not exclude smokers, and its findings may be slightly difficult to apply to general populations.

In conclusion, pending further validation in prospective outcome-based studies, our data may be used as preliminary diagnostic values of BPLab ABPM additional index in adult subjects.

\section{Acknowledgments}

This work is published on behalf of all the BPLab-Vasotens registry collaborators. Members of the BPLab-Vasotens Registry group are as follows: Hemodynamic Laboratory Ltd, Nizhniy Novgorod, Russia: Igor N Posokhov and Georgy D Nesterov; Universitätsklinikum SchleswigHolstein, Campus Lübeck, Med Klinik II, Lübeck, Germany: Johannes Baulmann; Cardiology Research and Production Complex, Moscow, Russia: Anatoly N Rogoza; People's Friendship University of Russia, Medical Faculty, Moscow, Russia: Zhanna D Kobalava and Yulia V Kotovskaya; Almazov Federal Heart, Blood and Endocrinology Centre, Saint-Petersburg, Russia: Aleksandra O Konradi, Eugeny V Shlyakhto, and Oleg V Mamontov; Petrozavodsk State University, Petrozavodsk, Russia: Viktoria A Korneva and Tatyana Y Kuznetsova; 3rd Republican Hospital, Saransk, Russia: Natalya N Kulikova and Irina V Starchenkova; Department 65 Competitive system analysis, National Research Nuclear University MEPhI, Moscow, Russia: Artemy V Orlov; Chelyabinsk State Medical Academy, Chelyabinsk, Russia: Elena A Grigoricheva and Vitaly V Evdokimov; The hospital within the Russian Railroad Network, Chita, Russia: Evgeniya N Bryantseva, Vitaliy S Barkan, Vladimir V Gorbunov, and Sergey A Alekseev.

\section{Disclosure}

The authors report no conflicts of interest in this work.

\section{References}

1. O'Brien E, Parati G, Stergiou G, et al; European Society of Hypertension Working Group on Blood Pressure Monitoring. European society of hypertension position paper on ambulatory blood pressure monitoring. J Hypertens. 2013;31(9):1731-1768.

2. Mancia G, Fagard R, Narkiewicz K, et al; Task Force Members. 2013 $\mathrm{ESH} / \mathrm{ESC}$ Guidelines for the management of arterial hypertension: the Task Force for the management of arterial hypertension of the European Society of Hypertension (ESH) and of the European Society of Cardiology (ESC). J Hypertens. 2013;31(7):1281-1357. 
3. Luzardo L, Lujambio I, Sottolano M, et al. 24-h ambulatory recording of aortic pulse wave velocity and central systolic augmentation: a feasibility study. Hypertens Res. 2012;35(10):980-987.

4. Posokhov IN. Pulse wave velocity 24-hour monitoring with one-site measurements by oscillometry. Med Devices (Auckl). 2013;6:11-15.

5. Koudryavtcev SA, Lazarev VM. Validation of the BPLab $\left({ }^{\circledR}\right)$ 24-hour blood pressure monitoring system according to the European standard BS EN 1060-4:2004 and British Hypertension Society protocol. Med Devices (Auckl). 2011;4:193-196.

6. Ageenkova OA, Purygina MA. Central aortic blood pressure, augmentation index, and reflected wave transit time: reproducibility and repeatability of data obtained by oscillometry. Vasc Health Risk Manag. 2011;7:649-656.

7. Rogoza AN, Kuznetsov AA. Central aortic blood pressure and augmentation index: comparison between Vasotens ${ }^{\circledR}$ and SphygmoCor ${ }^{\mathbb{R}}$ technology. Res Rep Clin Cardiol. 2012;3:27-33.

8. Posokhov IN, Konradi AO, Shlyakhto EV, Mamontov OV, Orlov AV, Rogoza AN. Day-to-day repeatability of the Pulse Time Index of Norm. Med Devices (Auckl). 2014;7:29-33.

9. Reference Values for Arterial Stiffness' Collaboration. Determinants of pulse wave velocity in healthy people and in the presence of cardiovascular risk factors: 'establishing normal and reference values'. Eur Heart J. 2010;31(19):2338-2350.

10. Magalhães P, Capingana DP, Silva AB, et al. Age- and gender-specific reference values of pulse wave velocity for African adults: preliminary results. Age (Dordr). 2013;35(6):2345-2355.
11. Farro I, Bia D, Zócalo Y, et al. Pulse wave velocity as marker of preclinical arterial disease: reference levels in a uruguayan population considering wave detection algorithms, path lengths, aging, and blood pressure. Int J Hypertens. 2012;2012:169359.

12. Frink RJ. Gender gap, inflammation and acute coronary disease: are women resistant to atheroma growth? Observations at autopsy. J Invasive Cardiol. 2009;21(6):270-277.

13. Chen MA, Kawakubo M, Colletti PM, et al. Effect of age on aortic atherosclerosis. J Geriatr Cardiol. 2013;10(2):135-140.

14. Williams B, Lacy PS, Baschiera F, Brunel P, Düsing R. Novel description of the 24-hour circadian rhythms of brachial versus central aortic blood pressure and the impact of blood pressure treatment in a randomized controlled clinical trial: The Ambulatory Central Aortic Pressure (AmCAP) Study. Hypertension. 2013;61(6):1168-1176.

15. Mancia G. Ambulatory central blood pressure: a new opportunity for mechanistic and clinical cardiovascular research. Hypertension. 2013;61(6):1148-1149.

16. Chung JW, Lee YS, Kim JH, et al. Reference values for the augmentation index and pulse pressure in apparently healthy korean subjects. Korean Circ J. 2010;40(4):165-171.

17. Janner JH, Godtfredsen NS, Ladelund S, Vestbo J, Prescott E. Aortic augmentation index: reference values in a large unselected population by means of the SphygmoCor device. Am J Hypertens 2010;23(2):180-185.
Vascular Health and Risk Management

\section{Publish your work in this journal}

Vascular Health and Risk Management is an international, peerreviewed journal of therapeutics and risk management, focusing on concise rapid reporting of clinical studies on the processes involved in the maintenance of vascular health; the monitoring, prevention and treatment of vascular disease and its sequelae; and the involvement of

\section{Dovepress}

metabolic disorders, particularly diabetes. This journal is indexed on PubMed Central and MedLine. The manuscript management system is completely online and includes a very quick and fair peer-review system, which is all easy to use. Visit http://www.dovepress.com/ testimonials.php to read real quotes from published authors. 